\title{
Portable neutron generators of VNIIA and their applications
}

\author{
V.Mikerov * \\ All-Russian Research Institute of Automatics \\ Sushevskaya 22, 127055, Moscow, Russia \\ E-mail: vmiker@sci.lebedev.ru
}

\section{Yu.Barmakov}

All-Russian Research Institute of Automatics

Sushevskaya 22, 127055, Moscow, Russia

E-mail: vniia@vniia.ru

\section{E.Bogolubov}

All-Russian Research Institute of Automatics

Sushevskaya 22, 127055, Moscow, Russia

E-mail: vniia@vniia.ru

\section{V.Ryzhkov}

All-Russian Research Institute of Automatics

Sushevskaya 22, 127055, Moscow, Russia

E-mail: vniia@vniia.ru

\begin{abstract}
Practical application of neutron techniques is nowadays restricted by a lack of appropriate neutron sources. One of the perspective ways to meet the demand is the development of improved neutron generators based on sealed neutron tubes. This paper describes technical specifications of fast neutron generators based on vacuum, gas filled and "plasma focus" tubes produced by All-Russian Research Institute of Automatics (VNIIA). State of the art and their applications are considered as well.
\end{abstract}

International Workshop on Fast Neutron Detectors

University of Cape Town, South Africa

April 3-6, 2006

\section{* Speaker}




\section{Introduction}

Nowadays application of neutron technologies is restricted by a lack of adequate neutron sources. Nuclear reactors, accelerators, isotope sources, traditionally used as neutron sources, are somehow bounded to be applied in analytical and supervisory equipment that ought to be inexpensive, safe and available for a wide range of users. These requirements are well met by portable neutron generators, which are remarkable for:

- absence of radiation in off-state;

- small dimensions and weight;

- high tuning range and functionality;

- operational simplicity and safety.

Activities on development of portable neutron generators are carried on in VNIIA [1] during 45 years. The essential research, production and technology basis have been created over this period including development of high-voltage materials and units, special tritium handling areas. All this enables to steadily improve technical characteristics of generators and to respond opportunely to new consumer's demands.

The paper gives some review of types and specifications of VNIIA's generators and their applications.

\section{Types and specifications of VNIIA neutron generators}

By physical principle of operation all generators produced by VNIIA can be divided into 3 groups depending on the type of used sealed tube:

a) generators with vacuum tubes,

b) generators with gas-filled tubes,

c) generators with "plasma focus" tubes.

Till recently the first type generator was the main product. Its merits are:

- $\quad$ high neutron output per pulse (up to $10^{10}$ neutrons);

- $\quad$ high neutron output per input energy unit (up to $10^{8} \mathrm{n} / \mathrm{J}$ );

- absence of neutron radiation between pulses;

- $\quad$ user friendliness and reliability;

- high mechanical and environmental stability;

- relatively low price.

Demerits are restrictions on both frequency of neutron pulse generation (up to $100 \mathrm{~Hz}$ ) and pulse duration - typical duration of neutron pulse is equal to $1 \mu \mathrm{s}$.

VNIIA is engaged in production of 4 types of generators based on vacuum tubes (Table 1): 2 generators for logging equipment - ING-101 and ING-10-50-120 - and 2 generators for activation analysis - ING-013 and ING-03.

Advantages of generators based on gas-filled tubes, as compared to generators using vacuum tubes, consist in longer lifetime (more than 500 hours) and in possibility of wide-range control of neutron radiation parameters. 
Table 1. Performance attributes of ING with vacuumed tubes.

\begin{tabular}{|c|c|c|c|c|c|c|c|}
\hline Type & $\begin{array}{c}\text { Dimens., } \\
\text { mm }\end{array}$ & $\begin{array}{c}\text { Life time, } \\
\text { hours }\end{array}$ & $\begin{array}{c}\text { Output } \\
\text { n/pulse } \\
\text { (D-T) }\end{array}$ & $\begin{array}{c}\text { Pulse } \\
\text { repetition } \\
\text { rate, } \\
\mathbf{H z}\end{array}$ & $\begin{array}{c}\text { Pulse } \\
\text { duration, } \\
\mu s\end{array}$ & $\mathbf{T},{ }^{\circ} \mathrm{C}$ & $\begin{array}{c}\mathbf{P}_{\max }, \\
\mathbf{W}\end{array}$ \\
\hline ING-101 & \multirow{2}{*}{$\begin{array}{c}\varnothing 34 \\
L=1300\end{array}$} & 100 & $1 \times 10^{8}$ & $1 \div 20$ & 0.8 & $\begin{array}{c}-40 \\
+120 \\
\end{array}$ & \multirow{2}{*}{30} \\
\hline $\begin{array}{c}\text { ING -10- } \\
50-120\end{array}$ & & 75 & $1 \times 10^{8}$ & $1 \div 50$ & 0.8 & $\begin{array}{c}-40 \\
+120\end{array}$ & \\
\hline ING -013 & $\begin{array}{c}\varnothing 130 \\
\mathrm{~L}=1000\end{array}$ & 100 & $1 \times 10^{10}$ & $1 \div 100$ & 0.8 & $\begin{array}{c}0 \\
+40 \\
\end{array}$ & 300 \\
\hline ING -03 & $\begin{array}{c}\varnothing 130 \\
L=950\end{array}$ & 100 & $3 \times 10^{10}$ & $1 \div 100$ & 0.8 & $\begin{array}{c}0 \\
+40\end{array}$ & 500 \\
\hline
\end{tabular}

Four types of generators based on gas-filled tubes are now produced in VNIIA: 2 generators for oil geophysics - ING-06 and ING-08 - and 2 generators for ground-based analytical equipment - ING-07 and ING-17 (Table 2). Development of the last two generators was stimulated by a need for equipment to be used for identification of high explosives, chemical munitions, nuclear materials. ING-17 generator is intended for portable equipment, therefore its main advantage small size and weight. It is planned to use this generator in designing of autonomous small-sized neutron-analytical system for on-site control of objects, including field inspections.

Table 2. Performance attributes of ING with gas filled tubes.

\begin{tabular}{|c|c|c|c|c|}
\hline Type of generator & ING-06 & ING-07 & ING-08 & ING-17 \\
\hline $\begin{array}{c}\text { Maximum neutron } \\
\text { output (D-T), } \mathbf{n} / \mathbf{s}\end{array}$ & $1 \times 10^{8}$ & $1 \times 10^{9}$ & $5 \times 10^{7}$ & $5 \times 10^{8}$ \\
\hline \begin{tabular}{c} 
Neutron pulse width, $\boldsymbol{\mu s}$ \\
\hline $\begin{array}{c}\text { Neutron pulse repetition } \\
\text { rate, kHz }\end{array}$
\end{tabular}$\quad 0.4 \div 10$ & $0.1 \div 20$ & $0.4 \div 10$ & $0.1 \div 10$ \\
\hline $\begin{array}{c}\text { Life time (not less), } \\
\text { hours }\end{array}$ & 300 & 500 & 300 & 500 \\
\hline $\begin{array}{c}\text { Power consumption (not } \\
\text { more), W }\end{array}$ & 30 & 200 & 30 & 60 \\
\hline $\begin{array}{c}\text { Neutron unit } \\
\text { dimensions, mm }\end{array}$ & $\varnothing 70 \mathrm{~L}=1260$ & $\varnothing 190 \mathrm{~L}=440$ & $\varnothing 34 \mathrm{~L}=1820$ & $\varnothing 70 \mathrm{~L}=410$ \\
\hline
\end{tabular}


Third type generator (based on "plasma focus" chambers) is mainly known as an instrument for physical investigations and calibration of neutron detectors. This type generators produce nanosecond (10-20 ns) high-intensive neutron pulses, and typical size of neutron emitting region is about several millimeters. Their life time is limited by about 1000 pulses. At the moment the repetition rate of pulses is not more than one pulse per minute. VNIIA produces 2 types of generators (Table 3): ING-102 with output $10^{7} \mathrm{n} /$ pulse and ING-103 with output $10^{10} \mathrm{n} / \mathrm{pulse}$. Generator with output $10^{11} \mathrm{n} /$ pulse is now under development.

Table 3. Performance attributes of ING with "plasma focus" tubes.

\begin{tabular}{|c|c|c|c|}
\hline Type & $\begin{array}{c}\text { Maximum neutron output, } \\
\text { n/pulse }\end{array}$ & $\begin{array}{c}\text { Dimension, } \\
\mathbf{~ m m}\end{array}$ & $\begin{array}{c}\text { Weight, } \\
\mathbf{k g}\end{array}$ \\
\hline ING-102 & $1 \times 10^{8}$ & $\varnothing 290 \times 850$ & 29,5 \\
\hline ING-103 & $1 \times 10^{10}$ & $600 \times 400 \times 1300$ & 250 \\
\hline TGI 114 & $1 \times 10^{10}$ & $830 \times 630 \times 1300$ & 350 \\
\hline $\begin{array}{c}\text { TGI 181 (under } \\
\text { development) }\end{array}$ & $1 \times 10^{11}$ & $800 \times 1300 \times 1500$ & 600 \\
\hline
\end{tabular}

Generators with alpha-detector built in the neutron tube (ING-27) are new developments of VNIIA. Alpha-detector enables to specify direction and time of escape of a particular neutron. Chemical composition of the object is analyzed with the use of temporal and amplitude pulse analysis of gamma quanta emitted by the object due to irradiation by $14 \mathrm{MeV}$ neutrons. Such a technique improves by one-two orders signal-to-background ratio and thus increases significantly resolution and sensitivity of equipment. Specifications of the first experimental prototypes of such generators are as follows:

Neutron flux, n/s

Emission mode

Number of alpha detector pixels

Life time, hours

Power consumption, $\mathrm{W}$

Emission unit diameter ( $\mathrm{mm})$,

Length $(\mathrm{mm}) \mathrm{x}$ height $(\mathrm{mm})$

up to $1 \times 10^{8}$
continuous flux
up to 16
500
30
110
$190 \times 240$

Improvements of neutron generators with built-in $\alpha$-detectors are concerned with increasing neutron output up to $2 \times 10^{8} \mathrm{n} / \mathrm{s}$ and number of pixels up to 100 .

Among new VNIIA's developments is also a generator based on gas-filled tube with output up to $10^{11} \mathrm{n} / \mathrm{s}$. It is intended for neutron radiography, nuclear fusion investigations and treatment of oncological diseases. As for logging generators for oil geophysics, VNIIA makes every effort to improve their thermal stability up to $150^{\circ} \mathrm{C}$ at the first stage and up to $175^{\circ} \mathrm{C}-$ at the second stage. 


\section{Applications}

All range of tasks to be solved with the use of neutron generators can be divided into 7 groups:

1) Nuclear geophysical equipment for exploration and development of oil and gas fields and ore deposits.

2) Equipment for detection and control of dangerous substances - high explosives (HE), nuclear materials (NM), chemical toxic agents, drugs.

3) Neutron radiotherapy in cancer treatment.

4) Neutron radiography and tomography using thermal and fast neutrons.

5) Analytical equipment for monitoring production processes, elemental analysis of products and wastes (metals and alloys, fertilizers, agricultural products, industrial wastes).

6) Instruments for monitoring nuclear-dangerous objects containing fission materials: subcritical assemblies, cooling ponds for spent fuel, reservoirs with radioactive wastes etc.

7) Instruments and equipment for research.

As for geophysical equipment VNIIA proceeds successively from production of neutron tubes to production of special neutron generators, well logging instruments and finally to rendering of this equipment and services to oil companies. The range of produced well logging instruments enables to involve most of nuclear-physical methods.

The equipment produced by VNIIA is used for:

- development of oil and gas fields with mineralized stratal water;

- exploration and development of oil and gas fields with any salinity of stratal water;

- measuring concentrations of natural radioactivity elements (U, Th, K);

- localization of collectors, determination of porosity and saturation character.

Portable neutron generators offer new ways for solution of a wide range of anti-terrorist and other tasks:

- control of mail items, cases, luggage for detection of illicit substances (HE, toxic agents, NM, drugs);

- control of air, cargo, sea containers;

- identification of mines in walls and soil;

- identification of toxic agents in shells and other containers.

Results of VNIIA research on creation of radiography complexes based on portable neutron generators show that employment of generators with output of $10^{11} \mathrm{n} / \mathrm{s}$ gives good promise for the following applications of portable radiographic equipment:

- control of the state (integrity and relative position of rather large units and assemblies) of various articles before tests, after damage impacts (shocks, floods etc.), as well as warranty control;

- control of objects with metal casing opaque to X-rays;

- control of accuracy of fitting of pyrotechnic articles, containing metal components or encased in thick-wall bodies;

- control of impermeability of pyrotechnic and other articles by holding in pressurized water pool; 
- investigation of dynamic processes using neutron generators with "plasma focus" chambers;

- control of containers used for transportation of radioactive sources and materials;

- control of critical articles of aerospace industry (turbine blades, pyrotechnic items, helicopter vanes etc.).

Fig. 1 demonstrates potentials of portable radiographic equipment in controlling containers made of heavy metals.

A

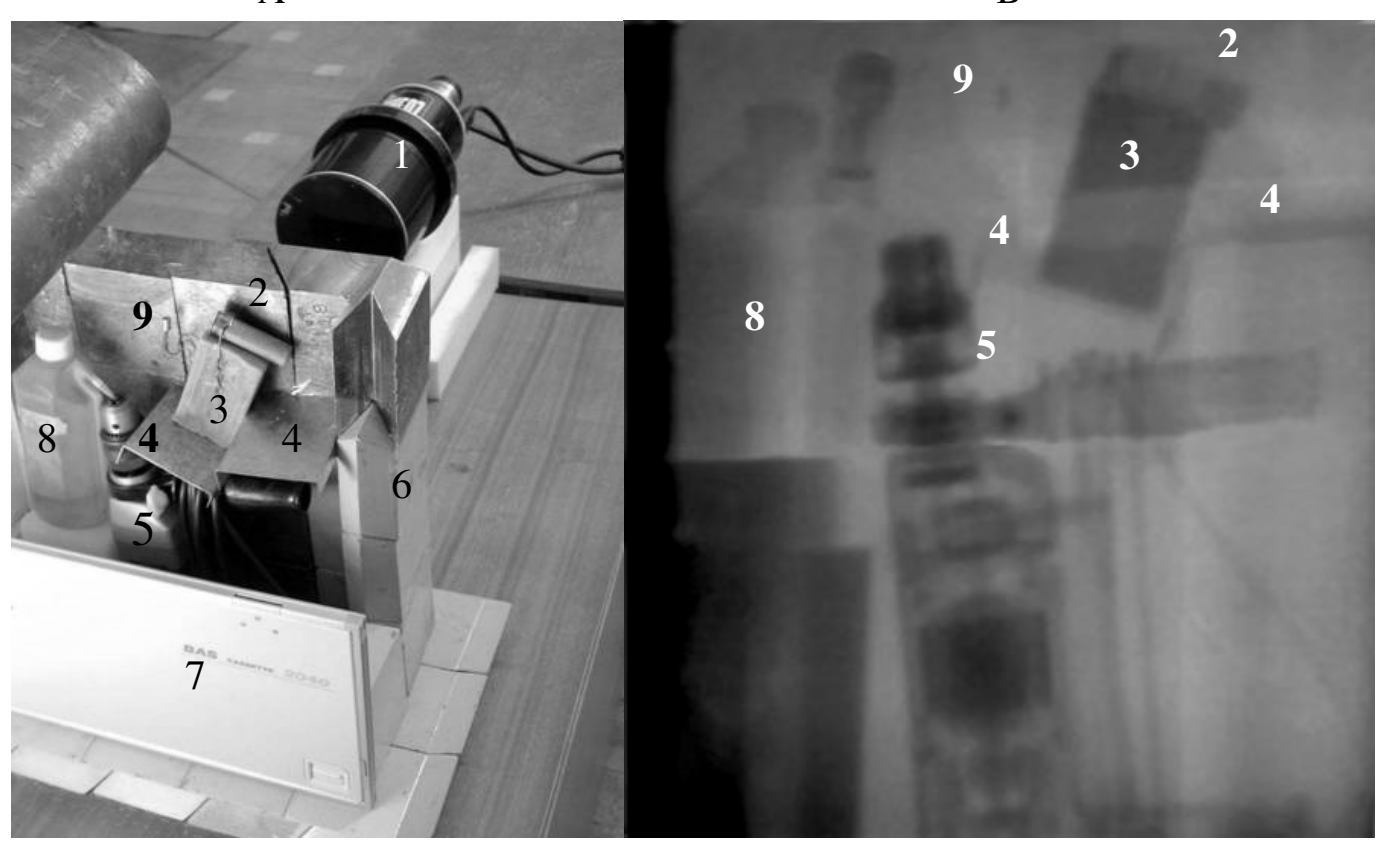

Fig. 1. A - photo of generator and objects arrangement, $\mathrm{B}$-radiographic image.

1 - ING-07, 2 - cartridge, 3 - soup, 4 - $2 \mathrm{~mm}$ thick tin plate, 5 - drill machine, 6 - lead bricks, 7 - cassette with a set of IP detectors, 8 - plastic bottle with alcohol, 9 - fuse dummy.

VNIIA is carrying out investigations on application of neutron generators in radiotherapy:

- remote therapy when collimator is placed between patient and neutron source;

- contact therapy when a source is placed on patient's body or is inserted into some cavity of patient's body;

- intratissue therapy when neutron source (generator target) is inserted into tumour via incision in the tissue.

One of the fields of VNIIA activities in development of research instruments is creation of new types of ionic sources, plasma focus chambers and equipment on their basis for investigation of magnetic field of the Earth. VNIIA collaborates with Space Research Institute in joint project "Dynamic Albedo of Neutrons" (DAN). VNIIA's neutron generator onboard the Mars rover in 
combination with the detector of reflected neutrons will enable to analyse composition of Martian soil for the presence of noticeable water quantities.

\section{Conclusions}

Portable generators of VNIIA are the result of more then 45 years activities in this field. The essential research, production and technology basis have been created over this period including development of special materials, electronic devices, high-voltage units, special tritium handling areas. Quality of products meets escalating requirements and determines a wide range of their applications. Prospects of further improvements of performance attributes of VNIIA's products concern with enlarging neutron output, life time, thermal stability and with the development of generators with in-built $\alpha$-detector.

\section{References}

[1] www.vniia.ru 